\title{
Adolescência(s): Produções e Atravessamentos Discursivos em Análise
}

\author{
Luciana Queiroz Fontenele ${ }^{1}$ \\ Universidade de Fortaleza, Fortaleza, CE, Brasil \\ Luciana Lobo Miranda \\ Universidade Federal do Ceará, Fortaleza, CE, Brasil
}

\begin{abstract}
Resumo
Este artigo apresenta o recorte de uma experiência de pesquisa-intervenção com um grupo de discussão composto por adolescentes de uma escola particular de Fortaleza. Tomando como referência a articulação entre discurso e modos de subjetivação em Foucault, a pesquisa teve como objetivo analisar e problematizar como estes estudantes são subjetivados pelos discursos que circunscrevem a adolescência na contemporaneidade. Na presente análise, cujo foco foram os discursos em que se evidencia a distinção entre uma adolescência mais favorecida socialmente e outra menos favorecida, esta comumente associada aos riscos e demais problemas sociais, foi possível perceber que as versões que os adolescentes constroem sobre si e sobre o outro adolescente são atravessadas pelos campos discursivos sociológico e midiático. No primeiro campo, destaca-se a relativização no que diz respeito à liberdade, responsabilidade e ao medo. No interior do discurso midiático os adolescentes se posicionaram agregando concepções excludentes sobre a gravidez na adolescência. A abertura para as mudanças e negociações em seus posicionamentos, engendrada no grupo de discussão, pôde promover deslocamentos discursivos, ampliando as possibilidades de constituição subjetiva para estes adolescentes.
\end{abstract}

Palavras-chave: Adolescência, discurso, pesquisa-intervenção, modos de subjetivação.

\section{Adolescence(s): Productions and Discussive Crossings in Analysis}

\begin{abstract}
This article presents a part of an experience of an interventionist-research in two adolescent groups in a private school in Fortaleza, Brazil. With reference to the articulation between speech and types of subjectivation in Foucault's theory, the research had the aim to analyze and problematize the way in which these students are subjetivized by the discourse which circumscribe the adolescence in the contemporary times. In the present analysis (which had the discourses that show the difference between a socially favorable adolescence and the one less favorable as the main focus), it was possible to verify that the versions the teenagers build about themselves and about the other teenagers are interfered by the mediatic and the sociologic discourses. In the first field, it is important to highlight the responsabilization related to the freedom, responsibility and fear. In the midst of the mediatic discourse, the teenagers declared their views adding up excluding conceptions about adolescent pregnancy. The openness they showed to changes and negotiations in their views, which were engendered in the discussion group,
\end{abstract}

Endereço para correspondência: Rua Afonso Celso, 196/702, torre 1, Aldeota, Fortaleza, CE, Brasil 60140190. Fone: (85) 99924-4567. E-mail: lucianaqf@unifor.br. 
might promoted discursive moves, which widen the possibilities of a subjective constitution to those teenagers.

Keywords: Adolescence, discourse, interventionist-research, types of subjectivation.

\section{Adolescencia(s): Producciones y Travesías Discursivas em Revision}

\section{Resumen}

El artículo presenta parte de una experiencia de investigación-intervención a través de dos grupos focales con adolescentes de una escuela privada en Fortaleza. Refiriéndose a la relación entre el discurso y las formas de subjetividad en Foucault, la investigación tuvo como objetivor analizar y discutir cómo estos estudiantes están subjetivada por los discursos que circunscriben la adolescencia en la sociedad contemporánea. En el presente análisis, la atención se centró en los discursos en que se destaca la distinción entre una adolescencia más favorecida socialmente y otra menos favorecida, esta comúnmente asociado con los riesgos y otros problemas sociales, se señaló que las versiones que los adolescentes construyen sobre sí mismos y sobre los otros están atravesadas por campos discursivos sociológico y mediáticos. En el primer campo, pone de relieve la relatividad en relación a la libertad, la responsabilidad y el miedo. Dentro del discurso mediático los adolescentes se colocaron agregando concepciones excluyentes sobre el embarazo en adolescentes. La apertura al cambio y negociaciones en sus posiciones, engendradas en el grupo de discusión, pudiera promover desplazamientos discursivos, ampliando las posibilidades de constitución subjetiva de estos adolescentes.

Palabras clave: Adolescencia, discurso, investigación de la intervención, modos de subjetividad.

Neste artigo é apresentado o recorte de uma experiência de pesquisa-intervenção com um grupo de adolescentes de uma escola particular de Fortaleza, no qual se buscou analisar e problematizar como são subjetivados e constroem discursivamente significados sobre ser adolescente na contemporaneidade. Tal pesquisa teve como produto a dissertação de mestrado intitulada: Eu adolescente, e o outro, diferente? Uma análise das produções discursivas de alunos de uma escola particular de Fortaleza. Na presente análise, cujo foco foram os discursos em que se evidencia a distinção entre uma adolescência mais favorecida socialmente e outra menos favorecida, esta comumente associada aos riscos e demais problemas sociais, foi possível perceber que as versões que os adolescentes constroem sobre si e sobre o outro adolescente são atravessadas pelos campos discursivos sociológico e midiático. No primeiro campo, destaca-se a relativização no que diz respeito à liberdade, responsabilidade e ao medo. No interior do discurso midiático, os adolescentes se posiciona- ram agregando concepções excludentes sobre a gravidez na adolescência, temática proposta para análise na pesquisa. A abertura para as mudanças e negociações em seus posicionamentos, engendrada no grupo de discussão, pôde promover deslocamentos discursivos, ampliando as possibilidades de constituição subjetiva para estes adolescentes.

A noção de discurso nesse estudo é tratada com base no referencial teórico de Foucault, filósofo que se dedicou à investigação da relação entre discurso e constituição do sujeito ou modos de subjetivação. Para problematizar como os adolescentes da pesquisa são subjetivados e constroem discursivamente significados sobre ser adolescente na contemporaneidade, no primeiro momento são apresentados alguns pressupostos teóricos acerca do discurso em Foucault, bem como uma breve explanação sobre a centralidade discursiva da adolescência na contemporaneidade. Em seguida, é delineado o percurso metodológico, com ênfase na pesquisa-intervenção e no grupo de discussão. Posteriormente, 
discutem-se alguns resultados analisados e apresentam-se as considerações a partir das análises.

\section{Discursos e Sujeitos: Como o Que se Diz Constitui o Que se É}

\section{Jogos Discursivos em Análise}

Por meio de um mapeamento das práticas sociais e tomando como base os próprios acontecimentos históricos, Foucault dedicou-se ao estudo das maneiras pelas quais se constituíram os sujeitos modernos, ou seja, aos diferentes modos pelos quais, em nossa cultura, o ser humano se torna sujeito. Parte, assim, da premissa de que não há o sujeito a priori, preexistente ao mundo social, rompendo com o cogito cartesiano. Para o filósofo, o saber científico inaugurado na modernidade faz nascer o sujeito indivíduo ao mesmo tempo em que nasce o sujeito objeto desse saber. O exercício de Foucault consistiu em escavar verticalmente o solo que deu origem a determinados tipos de saberes para compreender o que os sustentou durante sua existência, e desnaturalizá-los, ou seja, evidenciar as condições de emergência dos sujeitos no interior de tais discursos. Assim, por meio da análise histórica das práticas, Foucault quis mostrar, por exemplo, como o louco se transformou no doente mental.

Foucault (2009b) concebe o discurso como práticas que formam os objetos de que falam. $\mathrm{O}$ discurso não representa, mas cria o próprio objeto. Dessa forma, não há sujeito nem objeto a priori, mas ambos são construídos no interior dessas práticas, as quais, para Foucault, constituem uma dobra onde se articulam saberes e poderes produzidos histórica e culturalmente. Todas essas práticas são subjetivantes na medida em que fazem emergir um sujeito. Assim, Foucault relaciona discurso e o que designa como modos de subjetivação. $\mathrm{O}$ sujeito emergente é, ao mesmo tempo, objeto, pois o discurso constitui tanto o representado e o expressado quanto o sujeito que representa e expressa (Larrosa, 1994).

Partindo dessa premissa, compreende-se que, ao construírem significados sobre adolescência a partir dos vários discursos que os enredam na contemporaneidade, os adolescentes dos grupos de pesquisa falam de si e do outro, constituem-se e constituem o outro.

Para uma compreensão maior do exercício de análise do discurso na perspectiva foucaultiana, torna-se necessário esclarecer alguns termos que fazem parte de um vocabulário bem específico (mas não exclusivo) dessa análise: enunciado, sujeito, formação discursiva e campo discursivo. Segundo Fischer (2001), o enunciado é considerado a menor unidade de um discurso e constituído de elementos que garantem sua condição de existência, como a referência (a algo ou alguém), um sujeito que pode pronunciá-lo (não como indivíduo, mas como lugar que pode ser ocupado por determinados tantos outros sujeitos), o fato de estar sempre em relação com outros enunciados (de um mesmo campo discursivo - judiciário, econômico, político, jornalístico - ou não) e, por fim, a materialidade ou cena enunciativa, ou seja, a(s) forma(s) concreta(s) com que ele aparece. Percebe-se que sujeito e autor são conceitos que remetem a dois lugares diferentes, pois o primeiro referencia quem, de direito pode proferir o discurso em questão, constituindo uma função vazia ou um lugar de dispersão, de descontinuidade, pois há várias posições possíveis de serem assumidas por ele no discurso, assim como diferentes indivíduos podem assumir essa função (Foucault, 2009a).

As formações discursivas são as regras que determinam o que pode ou não ser dito no interior de determinada prática discursiva, conforme a posição que se ocupa dentro dela. Tais regras delimitam quais discursos assumem um lugar de vontade de verdade em diferentes contextos históricos e sociais, ou seja, o que evidencia alguns discursos em detrimento de outros, promovendo desnivelamentos entre eles.

Para entender como ocorrem os desnivelamentos entre os discursos, ou entre os enunciados dentro de um mesmo campo discursivo, é preciso evidenciar as condições de sua emergência, como empreendido por Foucault. Assim, por exemplo, entendemos que na contemporaneidade o enunciado do adolescente como "menor" remete à ideia da marginalidade, objeto que perdeu o sentido de "estar à margem" 
para ser associado ao risco. A menoridade deveria ser compreendida apenas como um intervalo etário, concepção atribuída a todos os adolescentes. No entanto, as distintas práticas sociais que construíram o adolescente discursivamente como menor, o aprisionaram no lugar do perigo, perigo este que também é colado à pobreza. Tem-se, portanto, uma rede de significados que são atribuídos naturalmente à adolescência pobre. Tal rede atravessa outros tantos discursos e nos atravessa subjetivamente, influenciando nossos modos de ser.

O estudo historiográfico de Foucault contribui de forma lúcida para mostrar que não há aleatoriedade na produção dos saberes, ajudando-nos a desnaturalizar os discursos e a dirigir nosso olhar para a relação entre as práticas discursivas e as diversas formas de poder que as permeiam. Partindo dessa relação, em especial no que ela permite articular discurso e sujeito, ou modos de subjetivação, cabe agora uma breve discussão sobre como historicamente a adolescência foi circunscrita no domínio dos saberes-poderes para que possamos entender como se constituem diferentes adolescências enquanto sujeitos e objetos dos discursos na contemporaneidade.

\section{Adolescência na Ordem do Discurso}

São muitos os discursos que constroem e definem a adolescência atualmente. Autores como Carvalho (2008), Fischer (1996) e Kehl (2004) apontam em seus estudos que a adolescência nunca esteve tão em alta, principalmente a partir da década de 60, quando se passou a valorizar tudo o que se refere a ela. A associação da juventude aos ideais de beleza e consumo, sendo a mídia poderoso instrumento de fortalecimento dessa associação, produz um modelo no qual todos se reconhecem. Pobres e ricos constroem significados sobre o que é ser jovem a partir desse modelo e constituem-se subjetivamente atravessados pelos discursos que o sustentam.

Além disso, há uma maior quantidade de jovens vivendo nas cidades, o que se intensificou no Brasil com o processo de redemocratização.
Esses fatores já justificariam o grande interesse em estudar a juventude. Mas são as produções de sentido atribuídas a tais fatores que estão na base desse interesse. Muitos autores como Carvalho (2008), Gonçalves (2005) e Pais (1990) afirmam que o interesse em estudar e falar sobre a juventude, tanto na Europa como no Brasil, insere-se numa lógica de controle dos excessos e vícios dessa mesma juventude (Gonçalves, 2005). Mas cabe perguntar, qual juventude? Se diferentes enunciados constroem diferentes objetos (jovens ou adolescentes), qual estaria no alvo dos estudos voltados às práticas de controle? Segundo Carvalho (2008), trata-se do jovem visto como um problema social, um gerador de riscos, ou seja, não daquele associado à beleza, liberdade ou ao consumo.

Pinheiro (2006) relaciona a recente valorização da adolescência com um movimento que vem consolidando a concepção de crianças e adolescentes como sujeitos de direitos. No entanto, fazendo um resgate dessa construção social, a autora lembra que, do período colonial até metade do século XX, no Brasil, predominaram outras concepções sobre a criança e o adolescente: como objetos de proteção, de controle e disciplinamento ou repressão social. Cada uma dessas concepções se fez presente em uma época específica e esteve associada a um conjunto de práticas segregatórias, que atribuíam à infância e à adolescência pobres um lugar discursivo de negatividade e, portanto, de exclusão. Os sentidos construídos e atribuídos à adolescência estão para além de uma visão naturalizada do que universalmente ocorre dentro de um intervalo etário. Os discursos psicológicos e biológicos, ainda amplamente utilizados para descrever características típicas da fase adolescente, referem-se a uma "natureza" jovial que acaba sendo restrita a determinado segmento social. O adolescente pobre é excluído desse quadro. Em geral, em nossa sociedade, cabe compreendê-lo dentro de outro referencial, o jurídico. Assim é que a primeira lei brasileira específica para a infância e a adolescência, o Código de Menores (criado em 1927 e reformulado em 1979), acabou legitimando uma construção da ideia do "menor" como aquele que 
é pobre e infrator. Mesmo com a substituição por "criança e adolescente" no texto legal do Estatuto da Criança e do Adolescente (Lei n. 8.069, 1990), o termo menor continua sendo utilizado para enunciar o pobre, em geral, situando-o no lugar discursivo do risco.

Como visto, os discursos emergem em determinado contexto engendrados pelas relações de poder sustentadas pelas sociedades e se dispersam sofrendo transformações em seu interior, já que não há unidade entre seus elementos. A mudança no enunciado provoca, no entanto, a mudança no objeto. Dessa forma, não é uma mesma adolescência enunciada de diferentes formas, mas adolescências distintas.

Levando em conta os vários sentidos atribuídos historicamente à adolescência e a compreensão de que tais sentidos estão arraigados em práticas de saber-poder, instituídas social e historicamente, nesse estudo buscou-se problematizar como os adolescentes mais favorecidos socialmente, estudantes de escola particular, posicionam-se nessa teia discursiva.

Não há critérios homogêneos no interior dos campos que delimitam o intervalo etário correspondente à adolescência e à juventude. Para a Organização Mundial da Saúde (OMS), por exemplo, o adolescente é o indivíduo no intervalo etário entre 10 e 19 anos, enquanto o Estatuto da Criança e do Adolescente (ECA) situa a adolescência entre os 12 completos e os 18 anos incompletos. Ariès (1981) refere-se à juventude como a idade privilegiada do século XVII, enquanto a infância é a do século XIX e a adolescência, do século XX. Kehl (2004) chama de juventude o período evolutivo entre a infância e a vida adulta que, a partir de 1950, passou a ser chamado de adolescência. Dessa forma, nesse estudo, os dois termos são utilizados conforme tratados no interior dos discursos ou pelos autores citados.

Vale ressaltar também que o recorte de classe social feito para esse estudo foi circunscrito à instituição de ensino onde os adolescentes estudam: a escola particular. Assim, todas as denominações em referência aos segmentos sociais mais favorecidos constituem inferências sobre o público que, de um modo geral, frequenta as escolas particulares (de médio ou grande porte) em Fortaleza.

\section{A Pesquisa-Intervenção e o Grupo de Discussão: Dispositivos Constituindo Sujeitos}

A pesquisa-intervenção, segundo Rocha e Aguiar (2003), rompe com os enfoques tradicionais de pesquisa, em que o pesquisador busca uma suposta neutralidade e distância com relação ao pesquisado. Além disso, amplia as bases teórico-metodológicas das pesquisas participativas, já que propõe uma transformação sociopolítica através da produção de conhecimento, do qual participam, mutuamente, pesquisador e pesquisado. Tal conhecimento se constitui como acontecimento do grupo na medida em que a intervenção desarticula práticas e discursos instituídos.

A ferramenta metodológica utilizada nesse trabalho foi o grupo de discussão. No bojo das pesquisas de intervenção, o grupo de discussão passa a ser usado na pesquisa social de campo por volta da década de 50 , sendo, no entanto, incorporado a um fundamento teórico-metodológico apenas no fim dos anos 70. Por conta da multiplicidade de experiências que o jovem vivencia em grupo, a partir de 80 o grupo de discussão passa a ser utilizado principalmente nas pesquisas sobre juventude (Weller, 2006).

Segundo Castro (2008),

os grupos de discussão propiciam que crianças e jovens se sintam mais potentes para intervir na tarefa solicitada pelos pesquisadores. Significa que eles vão promover deslocamentos e digressões naquilo que se estabelece como o objeto principal da discussão e do trabalho em grupo. (p. 36)

A implicação dos sujeitos no grupo de discussão, portanto, vai além da participação ativa. Eles se tornam agentes responsáveis pelo processo de pesquisa, colaboradores do movimento de produção de conhecimento junto ao pesquisador.

A opção por um trabalho de campo seguindo os pressupostos teórico-metodológicos da 
pesquisa-intervenção, por meio de grupo de discussão, tem sua justificativa no próprio objetivo da pesquisa: analisar e problematizar discursos, promovendo deslocamentos dos sujeitos em seus posicionamentos com relação a tais discursos. As práticas discursivas e não discursivas que emergem no grupo de discussão funcionam como dispositivos nos quais saberes e poderes vão sendo produzidos, articulando demandas que se atualizam. A intervenção vai além da pesquisa propriamente dita. Durante todo o processo, os adolescentes transitaram entre os lugares de sujeitos e objetos do discurso, atravessando e sendo atravessados por eles, constituindo-se e constituindo o(s) outro(s) adolescente(s). Da mesma forma acontece com o pesquisador. Nas palavras de Moraes (2011), "narrar é interferir". O exercício da palavra se transforma em campo de atividade. Assim, o que se produziu nessa pesquisa não é apenas transmitido por meio da escrita ou da fala, mas constitui uma prática que também produz (e transforma) realidades.

A pesquisa teve três etapas, assim denominadas: "captando adolescências", "analisando o que se diz", e, por fim, "videografando (e produzindo) adolescências". A primeira etapa buscava identificar ideias ou concepções que o grupo associava à adolescência e fazer uma exploração inicial sobre os discursos subjacentes a tais concepções. A segunda tinha como objetivos mapear para que analisassem alguns discursos produzidos na contemporaneidade sobre adolescência (jurídico, psicológico, biológico, midiático), refletindo sobre as vontades de verdade que os sustentam, identificar se reconheciam quais discursos atravessavam suas concepções e possibilitar que se posicionassem, fazendo deslocamentos com relação a tais concepções. No terceiro momento, a proposta era possibilitar que os membros vivenciassem várias adolescências, a partir de suas análises e construções anteriores, e pudessem problematizar o lugar que atribuem a cada adolescente (pensado por eles) no contexto do encontro das várias adolescências. Para efeito da construção desse artigo, são apresentados recortes de falas que circularam no grupo especialmente nas duas primeiras etapas.
$\mathrm{O}_{\text {grupo }}^{2}$ foi proposto na escola sob a forma de uma disciplina optativa da qual poderiam participar alunos do $7^{\circ}$ e do $8^{\circ}$ ano do Ensino Fundamental. A pesquisadora, que já havia trabalhado na referida escola (como psicóloga e professora), fez o convite apresentando como seria realizada cada etapa descrita acima. Após o prazo para as inscrições, foi formada a turma com quinze componentes, sendo sete meninas e oito meninos, todos no intervalo entre 13 e 15 anos. Foram realizados nove encontros com periodicidade semanal e duração de cinquenta minutos cada um. A partir desse ponto, a referência aos participantes é feita por meio de nomes fictícios, alguns dos quais escolhidos pelos próprios adolescentes.

\section{Resultados e Discussão}

\section{Adolescências Enunciadas nos Discursos Sociológico e Midiático: Elementos para uma Análise}

O Discurso Sociológico: Risco e Individualismo como Faces da Mesma Moeda. Segundo Pais (1990), historicamente a juventude vem sendo associada a problemas sociais, seja a delinquência, a marginalidade ou a dificuldade de entrada dos jovens no mercado de trabalho. $\mathrm{O}$ desemprego, ou o subemprego dificultam o acesso à habitação, promovendo o "esticamento" da permanência na casa dos pais, o que gera os conflitos familiares. Esse "esticamento" é tratado sociologicamente de duas formas distintas. Entre indivíduos de segmentos sociais privilegiados é vivenciado como um direito ao prolongamento da condição juvenil de não responsabilidade, tratado como uma moratória permitida antes da fase adulta. No entanto, a mesma experiência quando num contexto desfavorecido socialmente, coloca o jovem num lugar de instabilidade associada a problemas sociais.

2 Para saber como o grupo de discussão foi estruturado na forma de disciplina optativa e a respeito das implicações da relação da pesquisadora com os adolescentes enquanto ex-professora da escola, ler o terceiro capítulo de Fontenele (2013). 
Construída discursivamente no campo sociológico, a noção do jovem como risco na contemporaneidade é associada à ideia de individualismo. $\mathrm{O}$ individualismo, ou individualização traduz-se como uma suposta liberdade (diferente da modernidade clássica) em que o sujeito é o único responsável por suas escolhas. No entanto, por mais que a responsabilidade por estas escolhas seja cobrada de todos os jovens, as condições para lidar com tais responsabilidades não são oferecidas equitativamente, e os jovens em condições desiguais que permanecem por mais tempo na moratória - principalmente levando em conta que o mercado de trabalho demanda um aprimoramento cada vez maior na formação profissional, seja técnica ou acadêmica - passam a ser tratados como ociosos, "vagabundos", ou como um risco em potencial.

Tanto a noção de risco como a de individualismo tem origem na discussão sobre os conceitos Sociedade de Risco ou Modernidade Tardia, também denominada Modernidade Líquida por Bauman (2001). O escritor polonês faz uma análise das transformações sociais pelas quais passam as sociedades pós-modernas, utilizando a metáfora da liquefação para falar da mudança de paradigma, cuja marca é, exatamente, a perda dos referenciais da modernidade e o nascimento do individualismo. Nomeia sólida a primeira fase da modernidade, caracterizada pelo controle estatal e as normas industriais, quando a socialização era voltada à vida produtiva. Apesar da tediosa rotina de trabalho e da contraposição trabalho/capital, a estabilidade no trabalho e os vínculos corporativos conferiam certa segurança e tranquilidade ao sujeito. Para o autor, a redução do controle estatal e a consequente dissolução desse modelo relacional transformaram os sujeitos em individualistas, na medida em que cada um passou a ter que viver por conta própria.

A modernidade líquida, como tratada por Bauman (2001), recebe também a denominação de modernidade tardia ou reflexiva (Cohen \& Méndez, 2000) como efeito de um processo marcado por intensas evoluções industriais e tecnológicas ao longo da modernidade tradicional, que levam hoje as sociedades à autoconfrontação com as consequências dessas evoluções, sejam individuais ou coletivas. Tais consequências inserem a sociedade num contexto de riscos categorizados de três formas: (a) a degradação dos recursos naturais; (b) os perigos relacionados à insegurança social; (c) o desencantamento gerado pela dissolução dos referentes coletivos, esta última enfatizada por Bauman.

Embora sem aprofundar a respeito de todos os efeitos dessas mudanças, para este estudo, foi preciso analisar como elas estão imbricadas na constituição das várias formas de ser adolescente na contemporaneidade. A construção do que hoje se compreende como risco social, no contexto da dissolução dos referentes coletivos e da fluidez das relações, ajuda a pensar como se constitui discursivamente o sujeito adolescente como individualista ou como um risco em potencial. Assim, os vários discursos que enunciam a adolescência, seja associada ao consumo, às tecnologias, ou ao contrário, aos perigos, como uma ameaça ou um problema social, são permeados pelas práticas de poder instituídas socialmente. Tais temáticas emergiram na pesquisa, dando pistas de como os adolescentes de classe média vivenciam e são subjetivados pelos discursos que produzem estas realidades no contexto de suas experiências.

No primeiro módulo do grupo de discussão, duas temáticas que os participantes associaram à adolescência foi "responsabilidade" e "liberdade". Criaram duas categorias com agrupamentos de palavras nas quais enunciaram a adolescência a partir desses dois conceitos.

Sobre o que denominaram como "responsabilidades na adolescência", tem-se:

"Eu acho que o adolescente vive praticamente pra estudar e pra se divertir. Não como ele se divertia brincando, como quando tinha dois aninhos, mas é diferente a forma de se divertir, tem as relações amorosas..." (Glauber).

A responsabilidade como objeto de seus discursos em associação com a adolescência é contextualizada na sua experiência de moratória, cuja obrigação é equilibrar os estudos com a diversão. 
Sobre a liberdade, discorrem:

"Mas a adolescência, dependendo da época, muda muito. Antigamente você podia sair, hoje em dia vocêfica mais em casa, mudou muito" (Amanda).

Eduardo discorda: "Não sei, acho que não tinham mais liberdade não, pelo menos não as meninas..."

Pelo que meu pai me conta, eu acho que a adolescência dele foi melhor do que tá sendo a minha, porque ele brincava na rua, ele dizia "mãe, eu vou ali", e ela deixava. Hoje em dia não, a sociedade tá mais perigosa, você não consegue sair muito, você depende muito de seus pais, tem que ir pra lugar fechado, tipo shopping, uma coisa assim... (Hermione)

A relativização no que diz respeito à liberdade tem a ver com as questões temporais e de gênero. Se antigamente havia mais liberdade porque era menos perigoso, a concessão de sair de casa parecia mais permitida ao segmento masculino, o que é traduzido na fala de Hermione sobre a adolescência do pai e a de Eduardo em referência às meninas. A segurança só é garantida nos espaços fechados, como a casa ou o shopping. Os pais aparecem como os autores dos discursos a respeito dos riscos que a rua representa, bem como o encontro com o "estranho". Além dos pais, a mídia é reconhecida como veiculadora de enunciados sobre os perigos. $\mathrm{O}$ grupo faz referência aos programas de telejornalismo policial que passam diariamente em todos os canais abertos: "É só passando tragédia, só não vê quem você não quer" (Sandra). Embora façam alusão à cidade em suas falas e a alguns lugares onde ficariam mais seguros, não restringem os riscos à periferia, ao contrário, dizem que atualmente "todo lugar é perigoso" (Hermione).

Ao serem questionados se todos os adolescentes que vivem nas grandes cidades estão sujeitos aos mesmos riscos, respondem:

Eu acho que, tipo, meu pai ajuda um menino que é da minha idade, que mora na rua, eu acho que, pra gente, o nosso cotidiano é isso, pra eles já faz parte do cotidiano deles, já estão acostumados, eles não têm medo, assim, não que a gente se acostume com o crime, mas pra gente é uma coisa incomum ver um assalto, pra eles não. (Hermione) Pra eles é uma coisa normal. Pra gente normal é sair do colégio, ir pra casa, ter o almoço, pra eles não. Pra eles, normal é trabalhar pra comprar o almoço, saber que não pode ir naquele canto porque tem um cara assim e tal... (Hermione)

"Eu acho que eles se acostumam. Porque a gente não tá acostumado em o pessoal ameaçar, pra eles é normal, porque normalmente eles vivem aquilo, pode acontecer todo dia" (Amanda).

Embora com direito também a ter medo, perspectiva na qual o jovem pobre sai do lugar de ameaçador e se transforma em vítima, na construção discursiva feita pelos adolescentes, acostumar-se com a pobreza é também acostumar-se com a violência, como se uma coisa fosse "naturalmente" agregada à outra. Mesmo quando se tentou problematizar essa naturalização, sustentaram a posição: "É o cotidiano deles mesmo" (Hermione); "É porque eles estão mais expostos" (Amanda). Reproduziram a associação entre pobreza e periculosidade propagada discursivamente ao longo do tempo nas sociedades ocidentais. Não posicionaram diretamente o adolescente pobre no lugar do perigo, mas em relação a ele, seu medo é mais legítimo por estarem submetidos a experiências diferentes por conta de sua pertença social.

Quando questionados sobre quem poderia representar esse perigo nas ruas, responderam:

$\dot{E}$, tipo, as pessoas veem um adolescente na rua, e vão logo fechando o vidro do carro, ai o pessoal diz: "ah, é preconceito, é preconceito", eu acho assim, com tudo isso que a gente vê acontecendo, adolescente assaltando, se aparece um adolescente da nossa idade, pode ser uma pessoa digna, uma pessoa honesta, mas você não tem como saber. (Hermione)

Nessa construção discursiva, o adolescente "de rua" é enunciado por Hermione como um risco em potencial. Tal enunciado é visto de forma naturalizada no grupo, como algo socialmente instituído e aceito, tanto que justificam as reações das pessoas, seja o preconceito ou o medo. 
Glauber exemplifica com a fala de um professor:

ele disse que vinha andando na rua, aí cruzou com um grupo de adolescentes negrinhos, aparentemente pobres, com roupa esfarrapada. O amigo dele perguntou: "será que são assaltantes?" Ele disse: "estamos sendo preconceituosos, só porque são pobres não quer dizer que vão assaltar a gente e tal'... Mas ai assaltaram!.

Ao mesmo tempo em que relataram a experiência do professor como algo que justifica o medo e a desconfiança, não consideram ser necessária a vivência de uma situação de perigo para que sintam medo, confirmando que a mídia e os pais são incansáveis no papel de enunciar sobre os riscos. No entanto, o discurso já enraizado dos pais e da mídia é ressignificado na fala de um professor, um adulto de referência para eles e que discorre abertamente sobre seus preconceitos, medos e experiências com os riscos que a convivência com o outro pode provocar. O lugar que o professor ocupa nesse discurso confere legitimidade a tal discurso, que adquire o estatuto de vontade de verdade em relação ao da mídia, já desqualificado por banalizar a violência (nas palavras de Sandra: "só não vê quem não quer"), e dos pais, cuja verdade pode ser atravessada pela intenção de proteger os filhos.

Hermione tenta fazer um contraponto a partir da sua convivência com adolescentes pobres, no entanto, o enunciado é construído no interior de um discurso filantrópico. Em determinado momento do grupo, ela referiu-se ao adolescente de sua idade que o pai ajuda da seguinte forma: "Quando a gente chega lá, é a maior alegria. Eu acho que se você souber conviver, é a melhor coisa". Evidenciou uma nítida separação entre as duas experiências, colocando-se no lugar de quem só dá, não ganha com essa experiência, como se a convivência fosse uma concessão que depende dela e da qual só o outro se beneficiaria. Percebe-se que "a gente" e "eles" são tratamentos discursivos, como blocos homogêneos, ou ainda, duas categorias que agrupam, de um lado, os mais favorecidos, do outro, os menos favorecidos socialmente, independente dos diversos atravessamentos que vivenciam e que podem não estar associados à pertença de classe. No interior do discurso filantrópico, que é amplamente exaltado como regime de verdade, sobremaneira pela mídia, constrói-se um enunciado que só acentua as diferenças, as exclusões, no entanto revestido de "boas maneiras".

O Discurso da Mídia sobre Gravidez Precoce: Ensinando Modos de ser Adolescente. A celeridade com que as mídias vêm adentrando a vida dos sujeitos nas sociedades ocidentais é fenômeno indiscutível e temática amplamente debatida no interior de vários campos discursivos, como o psicológico, sociológico, filosófico, além das suas intersecções. Uma extensão dessa discussão contempla especialmente a centralidade das mídias no contexto da infância e da adolescência contemporâneas. Segundo Castro (1998), um dos motivos que aproxima crianças e adolescentes das novas mídias é o fato de terem menos oportunidade de brincadeiras ao ar livre e, paralelamente, menos convivência diária com os pais ou outros adultos responsáveis. Assim, a TV, por exemplo, assume o status de uma nova "pedagogia", concorrendo na construção de valores, com a educação familiar e escolar. Mais recentemente, a TV sai da própria TV para ser vista em aparelhos de celular, Ipads e computadores, outros aparatos dos quais crianças e adolescentes rapidamente se apropriam. Para Castro (1998), o aumento da exposição desses sujeitos à televisão, não só concorre com a família e a escola, como instaura novas percepções que eles passam a ter de si mesmo e dos outros, bem como do mundo que os cercam. Além da $\mathrm{TV}$, atualmente tem-se a internet, que torna mais veloz o fenômeno da publicização do cotidiano. Os adolescentes hoje assistem, compartilham e vivenciam experiências em que os flagras do seu dia a dia, seja um assalto, um escorregão ou a intimidade de uma figura pública, têm propagação em âmbito mundial e quase em tempo real.

Fischer (2002a, 2002b) toma de Foucault o conceito de dispositivo e engendra o termo "dispositivo pedagógico da mídia" para mostrar como a mídia (em especial, a televisiva, que é objeto de sua análise) constrói subjetividades na medida em que produz e faz circular saberes, 
valores e concepções. Por meio de suas estratégias de linguagem ou, como denomina Fischer (2002a), "estratégias de subjetivação", ensina e produz modos de ser que competem com as formas de educação escolar e familiar, alcançando principalmente os mais jovens. Segundo a autora, o dispositivo constitui um aparato discursivo e não discursivo que propõe uma multiplicidade de regras e "práticas de si", ou seja, que circunscrevem o sujeito em determinando campo de subjetivação, incitando-o a um tipo de "relação consigo" pela qual toma para si determinados modos de agir. Nesse conjunto de prescrições, a TV opera inclusões e exclusões, pois há definições a respeito do que cabe a determinados grupos sociais em virtude, por exemplo, de sua classe elou gênero. Assim, como ilustra a autora, a fala de uma modelo sobre sua gravidez precoce é revestida de uma permissividade que é negada à adolescente pobre, "cuja voz é captada pelo discurso do demógrafo, da socióloga e da psicóloga, atentos ao controle da sexualidade e da reprodução humana nas camadas populares" (Fischer, 1996, p. 209).

As disciplinas, portanto, ocupam um lugar de vontade de verdade, cuja intencionalidade, o controle, é o que se permite destinar para a adolescente pobre. Tratam-se dos mecanismos de exclusão e do desnivelamento dos discursos, estes que constroem, portanto, diferentes objetos. Na publicidade, por exemplo, a adolescência é sempre associada à beleza, saúde e vigor físico, enquanto nas matérias jornalísticas, está articulada a programas de governo ou empreendimentos do mundo do trabalho.

No segundo módulo do grupo de discussão, foram analisados dois blocos de vídeos produzidos e veiculados pela TV e/ou cinema. Todos exibiam temáticas relacionadas à adolescência e, o objetivo, nesse momento era que os adolescentes analisassem alguns discursos produzidos sobre adolescência (jurídico, psicológico, biológico, midiático), refletindo sobre as vontades de verdade que os sustentam, e que se posicionassem, fazendo deslocamentos com relação a tais concepções. Uma das temáticas foi a gravidez na adolescência, sobre a qual foram exibidos dois vídeos. Um ficcional, extraído do seriado
Malhação (Rios \& Alvarenga, 2012), outro com as primeiras cenas do Documentário brasileiro Meninas (Werneck, 2005), que apresenta casos reais de gravidez na adolescência no subúrbio carioca. Embora sejam materiais com diferentes naturezas discursivas, visto um ser uma produção televisiva e o outro cinematográfica, foram escolhidos por retratarem versões distintas sobre a experiência da gravidez na adolescência, especialmente por veicularem a gravidez da adolescente pobre como um problema social, objeto do documentário Meninas. A intenção era que o grupo percebesse e problematizasse as diferentes construções discursivas enunciadas nos discursos desenvolvimentistas (de base biológica e psicológica) e no sociológico (no qual a gravidez é tratada como um problema social de ordem pública) que atravessam o midiático.

O primeiro vídeo mostra o momento em que a personagem Cristal descobre que está grávida e se dirige à amiga Babi que presencia a realização do exame de farmácia dentro do quarto da adolescente. "Deu positivo... Positivo, Babi! Eu tô grávida! E agora, meu Deus?" A amiga Babi tenta consolá-la, ao mesmo tempo em que faz questionamentos do tipo "Por que você não se preveniu? Por que não usou camisinha?" Cristal chora, lamentando as perdas que a nova situação pode lhe propiciar: "Minha faculdade, a rádio, o meu futuro, a minha vida! Eu não me programei para isso".

O outro vídeo começa com uma fila de garotas num hospital público aguardando para fazer um exame de urina. A funcionária entrega um copinho de café para cada uma e orienta que vá ao banheiro urinar e colocar a fita (que indica ou não a gravidez de acordo com a cor). Em seguida, mostra os copinhos enquanto as adolescentes aguardam. A cena seguinte mostra toda a consulta ginecológica de Luana, 15 anos, 4 meses de gravidez. Primeiro, o próprio exame, depois, a entrevista da médica com as seguintes perguntas: "foi planejada?" Luana responde: "foi". Ela repete: "foi planejada, muito desejada?" A adolescente apenas balança a cabeça. Depois pergunta sobre os pais da menina. Quando Luana diz que o pai faleceu e que era traficante, insiste: "Era o que? Ah, traficante... ah, tá certo. Mata- 
ram ele?" Depois faz o ultrassom abdominal e, enquanto a garota sorri, ela pergunta? "Gostou?" "Legal, né?"

Ao serem questionados no grupo sobre as semelhanças e diferenças entre as histórias relatadas, responderam apenas que a gravidez da adolescente da Malhação não foi planejada e a outra foi. Não perceberam que o primeiro era ficção e o segundo real. Ao se discutir sobre como são produzidos e veiculados programas que tratam sobre gravidez de adolescentes de diferentes segmentos sociais, Amanda, em G2, relata sobre um documentário que viu, explicando:

"É muito diferente. A de classe alta quando contou pra mãe que tava grávida, foi horrivel, a mãe dela chorou, o pai ficou bravo, já a adolescente pobre quando foi contar, a mãe disse: 'tá bom'".

Ainda sobre os julgamentos que podem ser dirigidos às adolescentes que engravidam precocemente, Juliana complementou:

Eu acho que é uma questão de "lugar". Lá na sociedade pobre, talvez ninguém julgue ninguém, mas aqui, quando se diz que uma menina tá grávida, ahhh... As adolescentes de classe média se preservam mais, mas mais por causa da reputação do que por outro motivo.

O mesmo pensamento é compartilhado por Glauber:

"As adolescentes que têm mais dinheiro, normalmente elas têm mais educação e tem mais consciência. Não que elas não vão se desvirtuar, porque também tem adolescente rica engravidando, mas por uma questão de educação, as mais pobres engravidam mais" (Glauber).

Chacham, Maia e Camargo (2012) realizam uma investigação sobre a relação entre desigualdades de classe e gênero e algumas experiências que atravessam a gravidez precoce. Sinalizam que há prevalência da gravidez na adolescência entre as camadas mais pobres da população, mas, ao mesmo tempo, trazem dados de outras pesquisas que revelam, por exemplo, que não é algo necessariamente não desejado ou planejado. Outros pontos que a pesquisa apresenta, em geral, não são veiculados pela mídia, como por exemplo, o de que a quantidade de adolescentes que iniciam a vida sexual antes dos 17 é praticamente a mesma entre os grupos de camadas médias e os grupos de jovens residentes em favelas, bem como o dado de que ambos os grupos recebem a mesma quantidade de informações sobre contracepção. Um dos motivos por outro lado, que diferencia com relação ao uso dos métodos é a dificuldade de acesso aos serviços de saúde sexual para as jovens residentes em favelas. Outros dados importantes são os que indicam que as jovens residentes em favela em geral engravidam durante uma relação estável e, em sua maioria, a maternidade se concretiza. No contexto das adolescentes de classe média entrevistadas na ocasião da pesquisa, aproximadamente $50 \%$ das que engravidaram deram prosseguimento à gestação.

A temática da gravidez na adolescência, tão difundida na mídia, veste diferentes roupagens em se tratando de diferentes adolescências. Enuncia-se que gravidez na adolescência é precoce, o que é legitimado por vários discursos. $\mathrm{O}$ biológico defende que o corpo da adolescente pode não estar maduro para receber um feto, o que, portanto, implica em riscos para a vida da mãe e do bebê. O psicológico sustenta a versão de que a adolescente não tem maturidade emocional para assumir o ônus de criar um filho. $\mathrm{O}$ jurídico, além das implicações que já decorrem do fato de a adolescente não ser legalmente responsável por seus atos, nas situações em que a gestação é fruto de relação sexual com sujeito maior de idade, ainda há a inserção em crime de sedução. Todos, de um jeito ou de outro, concebem a gravidez como um fenômeno prejudicial ao desenvolvimento global da adolescente e associada a eventos também comumente propagados na mídia, como a realidade de abandono dos estudos e, muitas vezes, a separação entre a mãe e o pai da criança, com consequente destino dos cuidados endereçado aos avós.

Como ilustrado por Fischer (2001), evidenciando as diferentes constituições subjetivas e objetivas do discurso, a gravidez precoce da adolescente do subúrbio é captada pelo discurso do sociólogo e do psicólogo, no contexto discursivo do controle da sexualidade e natalidade. A gravidez da adolescente mais favorecida social- 
mente, em geral, aparece na ficção e é assunto de casa, compartilhado com os pais, e/ou uma amiga, como a personagem Cristal, da Malhação, enquanto a da adolescente pobre vira notícia, torna-se alvo de política pública. No documentário, que na primeira cena já mostra a realidade de exposição no hospital público (como o exame de urina coletivo), a publicização dessa vivência tão privada é ampliada, passando do público do hospital para o público nacional, e naturalizada. A materialidade do enunciado que constrói o objeto, no caso, a gravidez na adolescência, é regida por regras que viabilizam sua propagação e repetição. Miranda (2009) faz referência à presença cada vez mais maciça de especialistas em programas televisivos jornalísticos, como forma de dar tratamento científico aos temas e, através do sujeito autorizado a ocupar o lugar da enunciação, legitimar o que é propagado midiaticamente. As perguntas da médica, revestidas de certa ironia (Foi planejada, muito desejada? Legal, né? Gostou?), constituem uma sequência de signos que, produzida no interior do saber médico, transforma-se em verdade, com autorização inclusive para a expor a experiência de Luana no que ela poderia ter de mais íntimo.

\section{Considerações Finais}

Neste trabalho buscou-se problematizar como um grupos de adolescentes de determinada escola particular são subjetivados e constroem discursivamente significados sobre ser adolescente na contemporaneidade. Revelaram nas falas analisadas aqui especialmente o quanto são enredados pelas exclusões operadas nos discursos, procedimento o qual, como já explanado, faz emergir distintos objetos adolescência dentro de um mesmo campo discursivo. As diferenças engendradas pelos e nos discursos não foram percebidas pelos adolescentes. As exclusões nos enunciados veiculados sobre gravidez na adolescência, por exemplo, foram até naturalizadas por eles, que ainda agregaram, em sua leitura, interpretações também excludentes, como por exemplo, as de que as adolescentes pobres engravidam mais, bem como são "menos julgadas" por seus atos.
Segundo Castro (1998), a infância e a adolescência assumem hoje uma pluralidade de faces. Para a autora, "o consumo em massa, o viver numa grande cidade, a solidão na multidão, a expansão da comunicação pela mídia, a tecnificação e a informatização do nosso cotidiano" (p. 12) modificam as condições em que crianças e adolescentes constroem seu mundo interno e o mundo de suas relações sociais. Ao analisar o contexto em que vivem os adolescentes mais favorecidos socialmente na contemporaneidade, nos deparamos com a realidade do amplo contato com as tecnologias e as mais variadas possibilidades de consumo, ao mesmo tempo em que as trocas com o outro são restritas. Restritas pela sua pouca mobilidade na cidade, pela cultura do medo tão propagada hoje nas grandes metrópoles, e restritas também, muitas vezes, ao contato visual pela TV e/ou pela internet, locci nos quais os mais variados discursos são produzidos, misturados e veiculados.

As narrativas construídas pelos adolescentes dos grupos revelam o quanto são atravessados por sua própria experiência, dando pistas de como são subjetivados, nesse contexto, no interior das práticas discursivas e não discursivas instituídas socialmente. Assim, uma das pistas fornecidas por Hermione, é a de que o contato com adolescentes menos favorecidos socialmente pode mudar a forma como ela se constitui e constitui o outro, mesmo que, nesse momento, atravessado pelo discurso filantrópico.

É importante levar em conta o contexto discursivo em que tais construções emergiram. Os adolescentes estavam atravessados por três dispositivos, os quais, entre si, também se entrelaçavam: a câmera, a escola e a pesquisa. $\mathrm{Na}$ análise foucaultiana, "não se pode falar de tudo em qualquer circunstância" (Foucault, 2009a, p. 9), de modo a se fazer necessário reconhecer que os conhecimentos produzidos no grupo estavam circunscritos a determinadas condições. Além disso, segundo Foucault (2009b), a análise do discurso não implica investigar o que está nas entrelinhas, e sim as regras que sustentam o que é dito. Essa compreensão permeou as análises operadas na pesquisa. Não se tratou de julgar se o que os adolescentes diziam era verdadeiro ou 
não, pois, no grupo de discussão, na pesquisa intervenção e na análise foucaultiana aquela era a verdade produzida como acontecimento.

Segundo Fischer (2002b): "Modos de existência, aprendidos nas mais diferentes dinâmicas de poder e saber, jamais são totalmente compactos e definitivos; pelo contrário, sempre há neles interstícios, fendas, possibilidades éticas e estéticas não pensadas pelos saberes e poderes em jogo" (p. 154). Assim, ao se propor analisar e problematizar, por meio de um grupo de discussão, como adolescentes de determinada escola particular são subjetivados e constroem discursivamente significados sobre ser adolescente na contemporaneidade, o próprio dispositivo-grupo acabou por se configurar como um espaço de subjetivação. Ou seja, ao invés de paralisar as formas de ser, pensar e agir em um bloco discursivo compacto, homogêneo, único, o dispositivo-grupo produz uma teia que os enreda, ao mesmo tempo em que provoca aberturas para novas formas de pensar e agir sobre o mundo e sobre si mesmo. Ao colocar em evidência, através da discussão, alguns discursos que circunscrevem a adolescência na contemporaneidade, adolescentes operaram como agentes de mudança mesmo que em pequenas brechas ou janelas.

Da mesma forma, também o pesquisador se constitui e constitui o outro a partir do que narra, operando também como agente de mudanças. Como afirma Moraes (2011), “o pesquisador é um ator neste cenário - suas práticas produzem realidade". Assim, como subjacente à prática da pesquisa, o pesquisador "ganha" o não alcance do que propaga em suas narrativas.

\section{Referências}

Ariès, P. (1981). História social da criança e da família (2. ed.). Rio de Janeiro, RJ: LTC.

Bauman, Z. (2001). Modernidade líquida. Rio de Janeiro, RJ: Jorge Zahar.

Carvalho, M. J. F. L. de. (2008). Juventude e risco social: Uma questão de olhar(es)? Revista Virtual do Laboratório de Estudos da Violência e Segurança, 1(1), 43-52. Recuperado em http:// www2.marilia.unesp.br/revistas/index.php/levs/ article/view/762/664
Castro, L. R. (1998). Infância e adolescência na cultura do consumo. Rio de Janeiro, RJ: NAU.

Castro, L. R. (2008). Conhecer, transformar (-se) e aprender: Pesquisando com crianças e jovens. In L. R. de Castro \& V. L. Besset (Eds.), Pesquisa-intervenção na infância e juventude (pp. 2142). Rio de Janeiro, RJ: Trarepa.

Chacham, A. S., Maia, M. B., \& Camargo, M. B. (2012). Autonomia, gênero e gravidez na adolescência: Uma análise comparativa da experiência de adolescentes e mulheres jovens provenientes de camadas médias e populares em Belo Horizonte. Revista Brasileira de Estudos de População, 29(2), 389-407. doi:https://dx.doi. org/10.1590/S0102-30982012000200010.

Cohen, M. A., \& Méndez B., L. H. (2000). La sociedad del riesgo: amenaza y promesa. Sociológica, 15(43), 173-201. Recuperado em http://www. revistasociologica.com.mx/pdf/4308.pdf

Fischer, R. M. B. (1996). Adolescência em discurso: Mídia e produção de subjetividade (Tese de doutorado, Programa de Pós-Graduação em Educação, Universidade Federal do Rio Grande do Sul, Porto Alegre, RS, Brasil).

Fischer, R. M. B. (2001). Foucault e análise do discurso em educação. Cadernos de Pesquisa, 114, 197-223. doi:https://dx.doi.org/10.1590/S010015742001000300009

Fischer, R. M. B. (2002a). Uma análise foucaultiana da TV: Das estratégias de subjetivação na cultura. Currículo Sem Fronteiras, 2(1), 41-54. Recuperado em http://www.universidadenova.ufba. br/twiki/pub/GEC/TrabalhoAno2001/uma_analise_foucaultiana_da_tv.pdf

Fischer, R. M. B. (2002b). O dispositivo pedagógico da mídia: Modos de educar na (e pela) TV. Educação e pesquisa, 28(1), 151-162. Recuperado em http://www.revistas.usp.br/ep/article/ view/27882

Fontenele, L. Q. (2013). Eu adolescente, e o outro, diferente? Uma análise das produções discursivas de alunos de uma escola particular de Fortaleza (Dissertação de mestrado, Programa de Pós-Graduação em Psicologia, Universidade Federal do Ceará, Fortaleza, CE, Brasil).

Foucault, M. (2009a). A ordem do discurso. São Paulo, SP: Loyola.

Foucault, M. (2009b). Arqueologia do saber (7. ed.). Rio de Janeiro, RJ: Forense. 
Larrosa, J. (1994). Teconologias do Eu e Educação. In T. T. da Silva (Ed.), O sujeito da educação - Estudos foucaultianos (pp. 35-83). Rio de Janeiro, RJ: Graal.

Lei n. 8.069, de 13 de Julho de 1990. (1990). Dispõe sobre o Estatuto da Criança e do Adolescente e dá outras providências. Recuperado em http:// www.planalto.gov.br/ccivil 03/Leis/L8069.htm

Rios, L. H., \& Alvarenga, J., Jr. (Diretores). (2012). Cristal descobre que está grávida [Vídeo]. Rio de Janeiro, RJ: Rede Globo. Recuperado em http://gshow.globo.com/novelas/malhacao/2011/Vem-por-ai/noticia/2012/02/cristal-descobre-que-esta-gravida.html

Gonçalves, H. S. (2005). Juventude brasileira, entre a tradição e a modernidade. Tempo Social, Revista de Sociologia da USP, 17(2), 207-219. Recuperado em http://www.revistas.usp.br/ts/article/ view/12476

Kehl, M. R. (2004). A juventude como sintoma da cultura. In R. Novaes \& P. Vannuchi. (Eds.), Juventude e sociedade: Trabalho, educação, cultura e participação (pp. 89-114). São Paulo, SP: Fundação Perseu Abramo.

Miranda, L. L. (2009). Linguagem e modos de subjetivação na relação práticas escolares e televisão. O Público e o Privado, 14, 165-177. Recuperado em http://www.seer.uece.br/?journal=opubli coeoprivado\&page $=$ article\&op $=$ view $\&$ path $\% 5$ $\mathrm{B} \% 5 \mathrm{D}=97$

Moraes, M. (2011). Pesquisar: Verbo ou substantivo? Narrativas de ver e não ver. Pesquisas e Práticas Psicossociais, 6(2), 174-181. Recuperado em http://www.ufsj.edu.br/portal2-repositorio/File/ revistalapip/volume6_n2/Moraes.pdf
Pais, J. M. (1990). A construção sociológica da juventude - Alguns contributos. Análise Social, 25, 105-106. Recuperado em http://analisesocial.ics.ul.pt/documentos/1223033657F3sBS8rp 1Yj72MI3.pdf

Pinheiro, A. A. A. (2006). Criança e adolescente no Brasil: Porque o abismo entre a lei e a realidade. Fortaleza, CE: Editora da Universidade Federal do Ceará.

Rocha, M. L., \& Aguiar, K. F. (2003). Pesquisa-intervenção e a produção de novas análises. Psicologia: Ciência e Profissão, 23(4), 64-73. Recuperado em http://www.scielo.br/scielo.php?script $=$ sci_arttext\&pid $=$ S1414-98932003000400010

Weller, W. (2006). Grupos de discussão na pesquisa com adolescentes e jovens: Aportes teórico-metodológicos e análise de uma experiência com o método. Educação e Pesquisa, 32(2), 241-260. Recuperado em http://www.scielo.br/pdf/ep/ v32n2/a03v32n2.pdf

Werneck, S. (Diretor). (2005). Meninas [DVD]. Rio de Janeiro, RJ: Cineluz.
Recebido: 27/01/2015

$1^{a}$ revisão: $10 / 07 / 2015$

$2^{a}$ revisão: $20 / 04 / 2016$

$3^{a}$ revisão: $22 / 04 / 2016$

Aceite final: 11/06/2016 